\title{
Critical appraisal of the role of serum albumin in cardiovascular disease
}

\author{
Shih-Chieh Chien ${ }^{1,2}$, Chun-Yen Chen², Chao-Feng Lin² and Hung-I Yeh ${ }^{2 *}$
}

\begin{abstract}
Concentration of serum albumin (SA), a multifunctional circulatory protein, is influenced by several factors, including its synthesis rate, catabolism rate, extravascular distribution, and exogenous loss. Moreover, both nutritional status and systemic inflammation affect the synthesis of SA. Determining SA concentration aids in risk prediction in various clinical settings. It is of interest to understand the prognostic value of SA in the full spectrum of cardiovascular disease (CVD) in the era of newly developed pharmacological and interventional treatments. Proper interpretation of SA in addition to established risk factors potentially provides a better risk discrimination and thereby presents an option to modify therapeutic strategies accordingly. In this narrative review, we summarize the basic features of SA and its associated physiological functions contributing to its prognostic impacts on CVD. Finally, we discuss the prognostic role of SA in CVDs based on existing evidence.
\end{abstract}

Keywords: Serum albumin, Cardiovascular disease, Prognosis, Literature review

\section{Background}

The properties and role of albumin have been explored for more than five centuries, since it was first precipitated from urine by Paracelsus [1]. Nowadays, we already have clarity on much of the information about albumin from studies carried out. Serum albumin (SA), the most abundant circulatory protein, is associated with several vital physiological functions, such as maintaining oncotic pressure and microvascular integrity, regulating metabolic and vascular functions, providing binding ligands for substances, antioxidant activities, and anticoagulant effects. Furthermore, SA is inversely related to inflammatory processes by modulating neutrophil adhesion and cell signaling moieties $[2,3]$.

SA is traditionally regarded as a biomarker for reliable risk prediction in various clinical settings. An increased risk in all-cause mortality and cardiovascular $(\mathrm{CV})$ mortality has been shown to be associated with low SA concentration [4]. In the current era, innovative revascularization procedures and emerging medical therapies have altered the clinical features of cardiovascular disease (CVD) and its prognosis. Hence, identifying new

\footnotetext{
* Correspondence: hiyeh@mmh.org.tw

${ }^{2}$ Cardiovascular Division, Department of Internal Medicine, MacKay Memorial Hospital, Mackay Medical College, No. 92, Sec. 2, Zhongshan N. Rd, Taipei City 10449, Taiwan, Republic of China

Full list of author information is available at the end of the article
}

biomarkers and re-evaluating the significance of traditional risk factors are important [5]. It is also interesting to understand the prognostic value of SA in the full spectrum of CVD so that the physicians can employ SA for risk prediction among selected populations and thereby offer an optimal therapeutic strategy accordingly.

This article reviews the basic concepts and the proposed functions of albumin, focusing on the link between SA and CVD based on existing evidence.

\section{Structure and biochemistry of albumin}

Albumin is a member of the albumin superfamily, which also includes the transport proteins $\alpha$-fetoprotein, vitamin D -binding protein (Gc-globulin), and afamin ( $\alpha$-albumin). Albumin is an aglycosylated, negatively charged protein consisting of 585 amino acids forming a single polypeptide chain of molecular weight $66.5 \mathrm{kDa}[6,7]$. The chain is composed of abundant charged residues such as lysine and aspartic acid and has no prosthetic groups or carbohydrate attached to it. Structurally, albumin has a heart shape in $\mathrm{x}$-ray crystallography (measuring $80 \times 30 \AA$ ) but in solution its conformation is ellipsoid [3]. The mature, circulating molecule is arranged in a series of $\alpha$-helices, stabilized by 17 disulfide bonds, and comprises three homologous domains (I-III). Each of these domains has two subdomains (A and B) composed of 4 and 6 
$\alpha$-helices, respectively. Albumin in solution is characterized by a flexible texture, owing to the presence of disulfide bonds between domains that confer ability to change between different conformational states. One unbound cysteine residue (Cys-34) in subdomain IA is a redox active thiol $(-\mathrm{SH})$ group. The thiol moiety is capable of thiolation (HSA-S-R) and nitrosylation (HSA$\mathrm{S}-\mathrm{NO}$ ) as well as binding of substances [7].

\section{Metabolism and distribution of albumin}

The total albumin pool is about $3.5-5 \mathrm{~g} / \mathrm{kg}$ body weight, of which $40-45 \%$ is present in the intravascular space and the remaining is present in the interstitial space [2]. The reference range for albumin concentrations in serum is approximately $3.5-5.0 \mathrm{~g} / \mathrm{dL}$ and the cases with the concentration less than $3.5 \mathrm{~g} / \mathrm{dL}$ is usually referred as hypoalbuminemia [8]. Albumin changes from intravascular to extravascular compartment at a rate of 5\%/ hour and the degradation corresponds to $5 \%$ of the daily whole-body protein turnover $[2,3]$ The transcapillary escape rate is increased in a variety of diseases [9]. In general, SA excretion via urine is minimal. This could be explained from its size and charge as well as its active reabsorption in renal tubuli [10]. Albumin is degraded into amino acids in all parts of the body. The biological halflife of SA is almost three weeks [10]. The amount of albumin metabolized, approximately $10 \%$ of the concentration per day under normal physiological conditions [9].

Synthesis of albumin occurs in the liver and is influenced by several factors, including diet and nutrition, colloidal oncotic pressure, exposure to hormones, and disease states (Table 1). Albumin synthesis may be suppressed by fasting or consumption of a protein-deficient diet [11], exogenous supply of substances raising colloidal oncotic pressure $[12,13]$, and comorbid diabetes or hepatic disease $[14,15]$. Conversely, albumin synthesis increase by consumption of a high-protein (amino acid) diet [11] and exposure to growth hormones, corticosteroids as well as insulin $[14,16,17]$.

\section{Biological functions of albumin Colloid oncotic pressure}

Albumin has lower molecular weight than the average of serum globulins but its concentration is higher conferring

Table 1 Factors influencing albumin synthesis

\begin{tabular}{ll}
\hline Factors that increase synthesis & Factors that decrease synthesis \\
\hline High-protein diet [11] & Protein-deficient diet [11] \\
High calories [11] & Fasting [11] \\
COP $\downarrow[12,13]$ & COP $\uparrow[12,13]$ \\
Growth hormone [15] & Diabetes [14] \\
Corticosteroids [16] & Hepatic disease [17] \\
Insulin [14] & Sepsis, trauma [2] \\
\hline
\end{tabular}

Abbreviation: COP colloidal oncotic pressure major osmotic significance, contributing to $80 \%$ of total plasma colloid oncotic pressure. The osmotic pressure from SA concentration alone accounts for approximately $60 \%$ of the total oncotic pressure and the remaining $40 \%$ is attributed to the negative charges surrounding the protein, which attract and retain cations, particularly $\mathrm{Na}+$ in the vascular compartment. This effect is so called the Gibbs-Donnan effect, which retains water and enhances the oncotic pressure [2].

\section{Binding capacities of albumin}

The presence of a net charge and the ligand-binding sites enable SA to bind to and transport various substances, either endogenous or exogenous, such as inorganic ions, trace elements, vitamins, fatty acids, bilirubin, hormones, thyroxine, steroids, and drugs. These important binding sites for different substances have been well studied [7]. The binding capacities are influenced by several factors such as SA concentration, comorbidities, or presence of competitive compounds [2].

\section{Blood viscosity and vascular function}

An animal study showed that lack of albumin reduced erythrocyte deformability and subsequently increased blood viscosity [18]. This phenomenon of low SA and high blood viscosity is also observed in patients with nephrotic syndrome [19]. Moreover, SA is suggested to maintain the permeability of the capillary membrane [20]. Furthermore, it is proposed that hypoalbuminemia impairs the vasodilatory response to nitric oxide (NO) [21].

\section{Antioxidant effects}

Oxidative stress, due to reactive oxygen species (ROS) or reactive nitrogen species (RNS), can inflict damage on molecules, leading to the accumulation of toxic end products causing cellular dysfunction. This has been implicated in the pathogenesis of inflammation and atherosclerosis. Physiologically, SA contains abundant thiol groups, accounting for $80 \%$ of the total thiols in plasma scavenging ROS or RNS [3]. Moreover, a number of albumin-bound substances, such as NO and bilirubin, possess antioxidant properties, contributing to additional protection from oxidative stress [22, 23].

\section{Anticoagulant effects}

Investigations have demonstrated that low SA concentration is related to attenuated fibrinolysis [24]. The bioavailability of prostacyclin (PGI2), a naturally occurring vasodilator and a potent inhibitor of platelet aggregation, is dependent on the albumin concentration [25]. SA is also proposed to have a heparin-like activity. This effect is possibly explained by the similarities in structure and net charge with heparin [2]. 
Inflammatory responses of serum albumin

The activation of inflammatory response leads to a relevant change in plasma proteins, cytokines, and complements. SA is a negative-phase protein whose concentration decreases in response to inflammation. Although the mechanisms are not completely clear, it is presumed that a large proportion of amino acid is utilized to synthesize positive-phase proteins rather than albumin in the liver during an inflammatory response [26]. This hypothesis is supported by the investigations on sialylated glycoproteins in serum. Some of the sialylated glycoproteins rapidly increase in response to the onset of inflammation and are regarded as an index of acute phase response [27].

\section{Regulating cholesterol transport}

Although albumin does not have specific binding sites for cholesterol, it is considered to be a regulator of cholesterol transport. Aqueous transfer is an important mechanism contributing to cellular cholesterol efflux and SA acts as a shuttle, enhancing aqueous diffusion. [28] Moreover, SA is showed specific binding to vesicles which contained cholesterol [29]. Study showed that cholesterol efflux reduced approximately $40 \%$ from fibroblasts in the absence of plasma albumin by immunoaffinity chromatography [30]. It is proposed that cholesterol flux between numerous cholesterol pools would be enhanced by SA, thereby facilitating the restoration of steady-state levels as cholesterol is metabolized [28]. This effect possibly aids in explaining the relationship between SA and CVD.

\section{Serum albumin and prognosis in cardiovascular disease}

SA concentration serves as a reliable prognostic factor for CVD since a serendipitous finding in 1989 [8]. Numerous studies were designed and performed with the purpose of explaining the mechanisms, verifying the relationship, and extending the applications to relevant fields (Fig. 1) (Table 2). In general, the association of low SA concentration and adverse outcomes is thought to be multifactorial. All the above mentioned biological functions of SA, including the maintenance of vascular integrity [20], vasodilatory effects [21], binding ability for toxins [22, 23], regulating cholesterol transport [28-30], anticoagulant effects $[2,24,25]$, and antioxidant capacities [2, 3, 22, 23], are implicated in the pathogenesis. Moreover, reduced SA concentration can also be the result of inflammatory conditions [26] or inadequate nutritional intake [11], rendering potential implications on the prognosis of CVD (Fig. 2).

\section{Albumin and mortality in the general population}

The majority of studies supported that lower SA concentration is associated with an increased risk of mortality.
Phillips et al. first conducted a population-based, prospective cohort study (British Regional Heart Study), involving 7735 middle-aged men with or without a preexisting disease to evaluate the correlation between SA concentration and mortality. As a result of an average 9.2 years of follow-up, SA concentration was found to be inversely correlated with all-cause mortality, CV mortality, cancer mortality in both the groups with or without a preexisting disease [8]. This result was further supported by another longitudinal analysis from National Health and Nutrition Examination Survey Epidemiologic Follow-up Study (NHEFS). SA concentration of $\geq 4.5 \mathrm{~g} /$ $\mathrm{dL}$ was associated with a reduced risk of all-cause mortality (RR: $0.73,95 \%$ CI: $0.62-0.85$ for men and RR: 0.71, 95\% CI: $0.59-0.85$ for women), CV mortality (RR: 0.69, 95\% CI: $0.55-0.85$ for men and RR: 0.74 , 95\% CI: $0.58-$ 0.96 for women) and non-CV mortality (RR: $0.77,95 \%$ CI: $0.61-0.97$ for men and RR: 0.66, 95\% CI: 0.50-0.88 for women) [31] Kuller et al. reported that SA concentration could be an independent predictor of mortality and morbidity in middle-aged men with a high risk of coronary heart events. The association was stronger for coronary heart disease deaths than for nonfatal myocardial infarction (MI) [32]. In the Paris Health Study, there was a significant inverse association observed between SA concentration and all-cause mortality in men, but not in women [33]. This result was contrary to that of the Framingham Offspring Study, which reported an inverse relation between SA concentration and mortality in women but not in men [34]. Results from a metaanalysis, including 8 prospective studies, have shown that subjects with SA levels in the bottom third (estimated $3.8 \mathrm{~g} / \mathrm{dL}$ ) have a 1.9-fold increased risk for allcause mortality and 2.0-fold increased risk for CV mortality, compared with those in the top third (estimated $4.2 \mathrm{~g} /$ dL) [4]. All the aforementioned studies were published before or around 2000. In a recent Japanese cohort study, low SA concentration independently predicted all-cause and cause-specific (cancer, infection and CVD) mortality after a long-term (15 years) follow-up [35].

\section{Albumin and coronary heart events in the general population}

Whether SA concentration could predict nonfatal coronary heart events is an interesting but controversial issue. In the Multiple Risk Factor Intervention trial and the Framingham Offspring study, there was a significant inverse relationship between SA concentration and risk of MI [32, 34]. In the Atherosclerosis Risk In Communities (ARIC) Study, low SA concentration was only associated with incident MI in individuals who were current smokers [36]. Moreover, low SA did not provide adequate predictive power for incident coronary heart events in the older populations (aged 65-74 years) in 


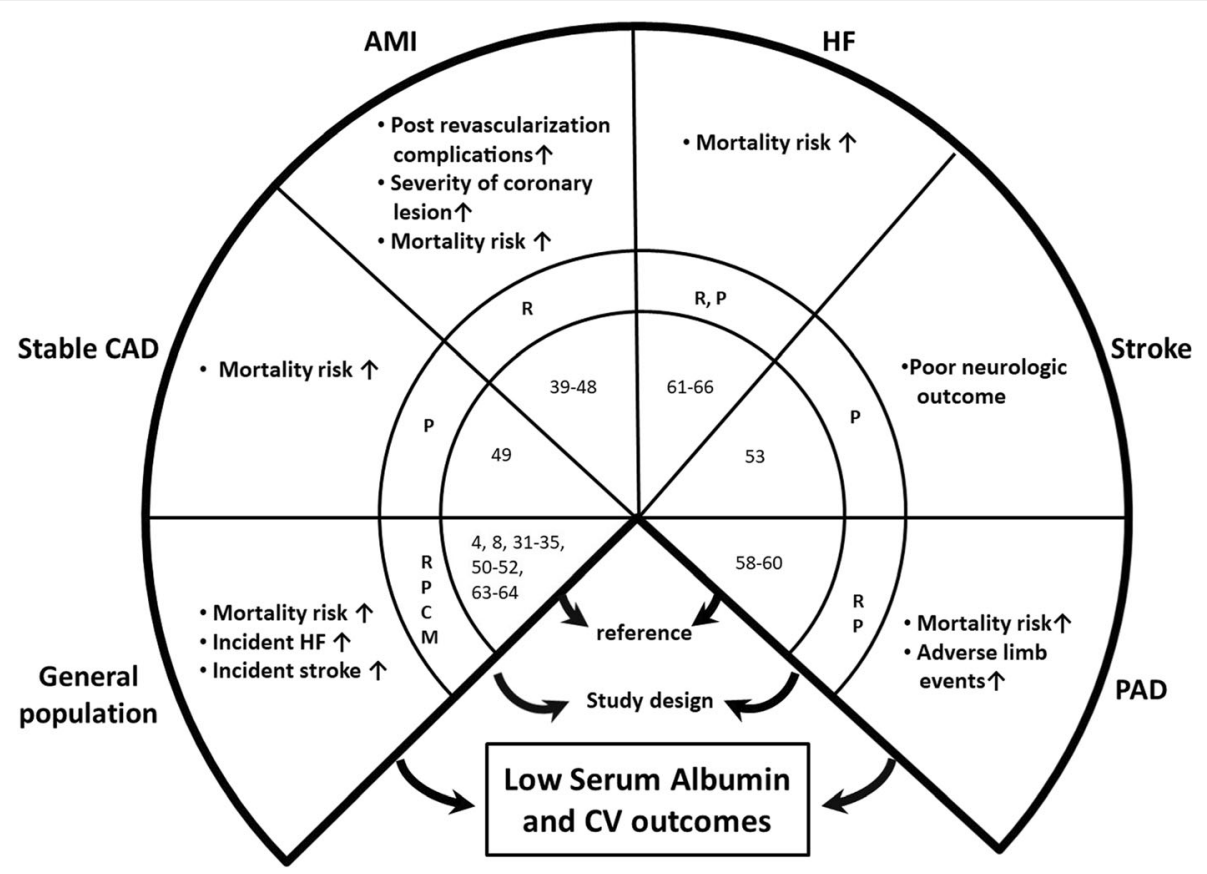

Abbreviation of study design R: Retrospective study; P: Prospective study; C: Cross-section study; M: Meta-analysis study

Fig. 1 Serum albumin and prognosis across the cardiovascular continuum. Abbreviation: CAD: coronary artery disease; AMl: acute myocardial infarction, HF: heart failure; PAD: peripheral arterial disease

NHEFS [31]. From a prospective study on the elderly (aged 65 years and older), low SA concentration was identified with a high risk for coronary heart events in women but not in men [37]. In Zutphen Elderly Study, SA only predicted the incidences of coronary heart events among men with elevated total cholesterol [38]. Thus, the risk discrimination of incident coronary heart events using SA concentration is not consistent and varies with different designs of studies. It is possible that low SA concentration does have a direct causative role for incident coronary heart events but could be an indicator of an underlying condition [34]. Similar to the previous section, all the data reviewed here were derived from studies published before or around 2000.

\section{Albumin and prognosis in coronary artery disease}

In the presence of effective pharmacological and interventional treatments for coronary artery disease (CAD) after the millennium, the prognostic value of SA has been emphasized further. Among individuals with an acute phase of CAD, SA is also reported as a strong prognostic factor [39-41]. Hartopo et al. evaluated small number patients with acute coronary syndrome (ACS) from a single center. Hypoalbuminemia $(<3.5 \mathrm{~g} / \mathrm{dL})$ measured upon admission was associated with inhospital adverse events, including death, acute heart failure, cardiogenic shock, and reinfarction. This association, however, is not significant by adjusting other risk factors (OR: 2.8, 95\% CI: 0.7-9.5) [42] Oduncu et al. retrospectively analyzed 1706 patients with ST-segment elevation myocardial infarction (STEMI) treated with primary percutaneous coronary intervention (PCI), and reported that hypoalbuminemia is associated with both in-hospital mortality and long-term mortality, with a median follow-up of 40 months (23.3 vs. $8.4 \%$, $P<0.001$ ). In a multivariate model, hypoalbuminemia independently predicted long-term mortality (HR: 2.98, 95\% CI: 1.35-6.58) [39]. The importance of SA in the older patients with STEMI was also demonstrated [40] Plakht et al. categorized SA concentration more delicately in patients with acute MI. They found that SA concentration upon admission provided clear risk discrimination for 10-year mortality [41].

Among patients undergoing isolated coronary artery bypass graft, higher preoperative SA concentration reduced the 30-day and/or in-hospital mortality and major complications [43]. Similar prognostic impacts were also reported among those undergoing PCI [44]. SA could be used as an important indicator of angiographic finding or adverse events associated with PCI. ACS patients with hypoalbuminemia had higher frequencies of multivessel disease, a higher thrombus burden, and a longer lesion length [39]. Low SA concentration( $<3.65 \mathrm{~g} / \mathrm{dL}$ ) was proposed as an independent predictor of high SYNTAX score $(\geq 33)$ and both factors, SA and SYNTAX score, were linked with the outcomes [45]. Moreover, SA 
Table 2 Clinical studies investigating the relation between serum albumin and cardiovascular disease

\begin{tabular}{|c|c|c|c|c|c|}
\hline Study & Year & Number & Characteristics of patients & Albumin cut-off value & Outcomes \\
\hline \multicolumn{6}{|l|}{ Coronary artery disease (CAD) } \\
\hline Hartopo et al. [42] & 2010 & 82 & ACS & $<3.5 \mathrm{~g} / \mathrm{dL}$ & $\uparrow \mid n$-hospital adverse event ${ }^{a}$ \\
\hline Bhamidipati et al. [43] & 2011 & 2794 & $C A D$ undergoing $C A B G$ & $<3 \mathrm{~g} / \mathrm{dL}$ & $\begin{array}{l}\uparrow \text { Mortality and post-operative } \\
\text { complications }\end{array}$ \\
\hline Oduncu et al. [39] & 2013 & 1706 & STEMI undergoing primary PCI & $<3.5 \mathrm{~g} / \mathrm{dll}$ & $\begin{array}{l}\uparrow 3.5 \text {-year all mortality and } \\
\text { advanced } \mathrm{HF}\end{array}$ \\
\hline Sujino et al. [40] & 2015 & 62 & Age $\geqq 85$ years, STEMl & Continuous variable & $\uparrow I n-h o s p i t a l$ mortality \\
\hline Murat et al. [46] & 2015 & 890 & ACS undergoing $\mathrm{PCl}$ & Continuous variable & $\begin{array}{l}\uparrow \text { Contrast induced acute kidney } \\
\text { injury and in-hospital mortality }\end{array}$ \\
\hline Kurtul et al. [47] & 2015 & 536 & STEMI undergoing PCl & $<3.75 \mathrm{~g} / \mathrm{dL}$ & $\uparrow$ Risk of no-reflow after PCI \\
\hline Plakht et al. [41] & 2016 & 8750 & AMI & $\begin{array}{l}\text { categorize albumin level } \\
\text { by } 3.4,3.7,3.9,4.1 \mathrm{~g} / \mathrm{dL}\end{array}$ & $\uparrow 10$-year all mortality \\
\hline Kurtul et al. [45] & 2016 & 1303 & $\begin{array}{l}\text { ACS undergoing coronary } \\
\text { angiography }\end{array}$ & $<3.3 \mathrm{~g} / \mathrm{dL}$ & $\begin{array}{l}\uparrow S Y N T A X \text { score and in-hospital } \\
\text { mortality }\end{array}$ \\
\hline Celik et al. [48] & 2016 & 341 & $\mathrm{PCl}$ with a BMS & $<3.81 \mathrm{~g} / \mathrm{dL}$ & $\begin{array}{l}\uparrow \text { Risk of in-stent restenosis after } \\
\mathrm{PCl}\end{array}$ \\
\hline Wada et al. [44] & 2017 & 2860 & $C A D$ undergoing $P C l$ & $3.8 \mathrm{~g} / \mathrm{dL} ; 4.1 \mathrm{~g} / \mathrm{dL}$ & $\uparrow M A C E$ and 10 -year all mortality ${ }^{b}$ \\
\hline Chien et al. [49] & 2017 & 734 & Stable CAD & $<3.5 \mathrm{~g} / \mathrm{dL}$ & $\uparrow 1.5$-year MACE and mortality ${ }^{c}$ \\
\hline \multicolumn{6}{|l|}{ Ischemic stroke } \\
\hline Gillum et al. [50] & 1994 & 4897 & $\begin{array}{l}\text { White men aged } 65-74 \text { years; } \\
\text { Blacks aged } 45-74 \text { years }\end{array}$ & $<4.2 \mathrm{vs}>4.4 \mathrm{~g} / \mathrm{dL}$ & $\begin{array}{l}\uparrow 14 \text {-year stroke incidence and } \\
\text { stroke mortality }\end{array}$ \\
\hline Dziedzic et al. [53] & 2004 & 759 & Acute ischemic stroke & $<4.9 \mathrm{~g} / \mathrm{dL}$ & $\begin{array}{l}\text { Poor 3-month neurologic } \\
\text { outcome }^{d}\end{array}$ \\
\hline Hostmark et al. [52] & 2006 & 5071 & $30-75$ years & $<4.7 \mathrm{~g} / \mathrm{dL}$ & $\uparrow$ (self-reported) Stroke incidence \\
\hline Xu et al. [51] & 2014 & 2986 & $>40$ years old & $<4.2 \mathrm{vs}>4.6 \mathrm{~g} / \mathrm{dL}$ & $\uparrow 12$-year stroke incidence \\
\hline \multicolumn{6}{|l|}{ Peripheral Arterial Disease (PAD) } \\
\hline O'Hare et al. [56] & 2002 & 14,427 & Hemodialysis patients & Continuous variable & $\uparrow P A D$ incidence \\
\hline Beddhu et al. [57] & 2002 & 1411 & Hemodialysis patients & $<3.6 \mathrm{~g} / \mathrm{dL}$ & $\uparrow P A D$ incidence \\
\hline Schillinger et al. [60] & 2004 & 702 & $\begin{array}{l}\text { PAD patients with less than } 2 \\
\text { traditional risk factors }\end{array}$ & $<3.85 \mathrm{~g} / \mathrm{dL}$ & $\uparrow 1$-year MACE ${ }^{\uparrow}$ \\
\hline Ishii et al. [59] & 2013 & 450 & $\begin{array}{l}\text { Hemodialysis patients undergoing } \\
\text { endovascular therapy }\end{array}$ & $<3.6 \mathrm{~g} / \mathrm{dL}$ & $\begin{array}{l}\uparrow 3 \text {-year major adverse limb } \\
\text { event }^{\mathrm{e}}\end{array}$ \\
\hline Tsai et al. [58] & 2015 & 444 & Hemodialysis patients & Continuous variable & $\uparrow 4$-year all or CV mortality \\
\hline \multicolumn{6}{|l|}{ Heart failure (HF) } \\
\hline Horwich et al. [61] & 2008 & 1726 & Systolic HF & $\leq 3.4 \mathrm{~g} / \mathrm{dl}$ & $\begin{array}{l}\uparrow 1 \text { - and } 5 \text { - year all mortality } \\
\uparrow U r g e n t \text { heart transplant }\end{array}$ \\
\hline Kinugasa et al. [63] & 2009 & 349 & Age $\geqq 65$, Acute HF & $<3.2 \mathrm{~g} / \mathrm{dL}$ & $\uparrow$ In-hospital mortality \\
\hline Uthamalingam et al. [64] & 2010 & 438 & Acute, systolic HF & $<3.4 \mathrm{~g} / \mathrm{dL}$ & $\uparrow 1$-year cardiac mortality \\
\hline Gopal et al. [67] & 2010 & 2907 & Aged $70-79$ years without $\mathrm{HF}$ & $<4.0 \mathrm{~g} / \mathrm{dl}$ & $\begin{array}{l}\uparrow 6 \text {-year HF risk but the risk } \\
\text { declined annually }\end{array}$ \\
\hline Filippatos et al. [68] & 2011 & 5450 & Aged $\geq 65$ years, without $\mathrm{HF}$ & $\leq 3.5 \mathrm{mg} / \mathrm{dL}$ & $\uparrow 10$-year HF incidence \\
\hline Liu et al. [62] & 2012 & 576 & Acute $\mathrm{HF}$, preserved EF & $\leq 3.4 \mathrm{~g} / \mathrm{dl}$ & $\uparrow 1$-year all mortality \\
\hline Polat et al. [65] & 2014 & 135 & Acute, systolic HF & $<3.1 \mathrm{~g} / \mathrm{dL}$ & $\uparrow 1$-year mortality \\
\hline Bonilla-Palomas et al. [66] & 2014 & 362 & Acute HF & $\leq 3.4 \mathrm{~g} / \mathrm{dL}$ & $\begin{array}{l}\text { } 1 \text { n-hospital and 1-year all } \\
\text { mortality }\end{array}$ \\
\hline
\end{tabular}

Abbreviation: STEMI ST-segment elevation myocardial infarction, $H F$ heart failure, $P C I$ percutaneous coronary intervention, $A M I$ acute myocardial infarction, $A C S$ acute coronary syndrome, $C A D$ coronary artery disease, $C A B G$ coronary artery bypass graft, $C V$ cardiovascular, MACE major adverse cardiac event, $B M S$ bare-metal stent, $P A D$ peripheral arterial disease, $E F$ left ventricular ejection fraction

Continuous variable is addressed if studies analyzed the influence of serum albumin with a manner of continuous variable instead of a definite cut-off value

${ }^{a}$ In-hospital adverse events include mortality, acute heart failure, cardiogenic shock, and reinfarction

${ }^{\mathrm{b}} \mathrm{MACE}$ include nonfatal myocardial infarction and mortality

"MACE include nonfatal myocardial infarction, nonfatal stroke and cardiovascular mortality

${ }^{\mathrm{d}}$ Poor neurologic outcome was defined as modified Rankin Scale $>3$ or mortality

${ }^{\mathrm{e}}$ Major adverse limb event was defined as a composite of target lesion revascularization, amputation and all-cause mortality

fMACE include a composite of nonfatal MI, coronary revascularization, and all-cause mortality 


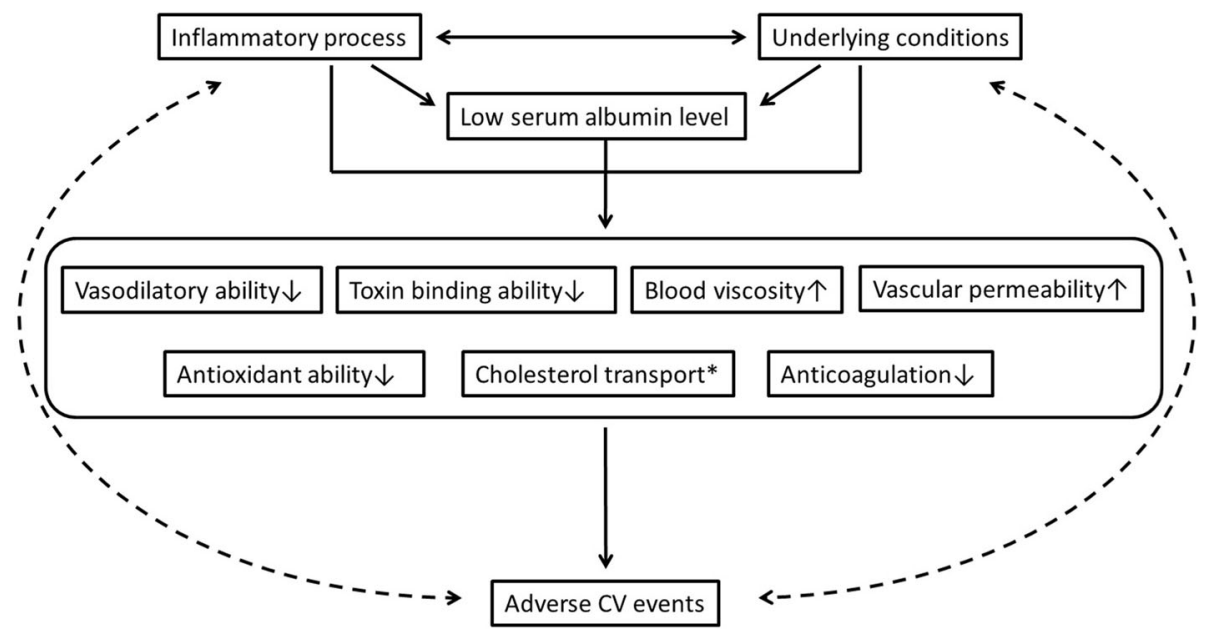

Fig. 2 Proposed interaction between serum albumin and CV outcomes. Abbreviation: CV: Cardiovascular. * Serum albumin is proposed to enhance cholesterol transport between numerous cholesterol pools, facilitating the restoration of steady-state levels as cholesterol is metabolized [28]

concentration on admission is inversely associated with post-PCI contrast-induced acute kidney injury in patients with acute coronary syndrome [46]. Furthermore, SA concentration is an important predictor of no-reflow phenomenon following primary PCI and in-stent restenosis rate after bare-metal stent implantation [47, 48].

We have recently reported the results of hypoalbuminemia and adverse CV outcomes in the Biosignature study, which enrolled CAD patients in stable condition at baseline prospectively. Patients with hypoalbuminemia had an increased risk of 1.5-year in major adverse CV events and in all-cause mortality (major adverse CV events, HR: 3.68, 95\% CI: 1.03-13.19; all-cause mortality, HR: 6.81, 95\% CI: 1.01-45.62) [49]. This study unequivocally confirms the important association between SA and individuals with chronic stable CAD.

\section{Albumin and prognosis in ischemic stroke}

Data from the First National Health and Nutrition Examination Survey (NHANES I) Epidemiologic Follow-up Study suggested that SA concentration $<4.2 \mathrm{~g} / \mathrm{dL}$ was associated with an increased risk of stroke incidence and death compared with $\mathrm{SA}>4.4 \mathrm{~g} / \mathrm{dL}$ in middle-aged white men and black men [50]. The inverse relation of reduced SA and incident stroke was also observed in two studies (the Northern Manhattan Study and the cross-sectional Norwegian Oslo Health Study) [51, 52]. Dziedzic et al. investigated 759 patients with acute ischemic stroke. The reduced risk of poor outcome, defined as modified Rankin Scale $>3$, or death was observed within the upper quartile of SA (OR: 0.43, 95\% CI: 0.26-0.7) [53]. Despite the apparent relations between higher SA concentration and better outcome from epidemiologic evidence, active therapy with albumin solution in acute ischemic stroke did not improve the outcome. This was true also for intracerebral hemorrhage and pulmonary edema where increased risk rates were identified $[54,55]$.

\section{Albumin and prognosis in peripheral arterial disease}

A cross-section investigation suggested SA concentration is also inversely associated with the incidence of peripheral artery disease (PAD) among patients undergoing hemodialysis [56]. Moreover, data from the HEMO study, enrolling 1411 patients undergoing hemodialysis, suggested that the risk for CVD linearly increased as albumin level decreased in patients with SA concentration $\geq 3.6 \mathrm{~g} / \mathrm{dL}$. The odds ratio with each $1 \mathrm{~g} / \mathrm{dL}$ increase in SA decreased by $61 \%$ for PAD, $68 \%$ for CAD, $67 \%$ for CVD, and 77\% for all atherosclerotic diseases [57].

Low SA concentration is associated with an increased risk of all-cause mortality among hemodialysis patients with PAD in a single center retrospective study [58]. It was also proposed as a single or add-on predictor of major adverse limb events, a composite of target lesion revascularization, amputation and all-cause mortality in hemodialysis patients undergoing endovascular intervention [59]. However, a prospective study enrolling angiographically proven PAD patients suggested that the prognostic value of SA in major adverse cardiac events, a composite of $\mathrm{MI}$, coronary revascularization, and allcause mortality was limited to the subjects who had only two traditional risk factors or less [60]. The prognostic effect of SA in PAD is attenuated when the severity or the complexity of comorbidities increases, contributing to a major impact on the outcomes.

\section{Albumin and prognosis in heart failure}

The development of heart failure (HF) can be the result of a sole cardiac disorder or, rather more often, the results from other CVD and impaired cardiac function 
and structure. Hence, the relationship between SA and $\mathrm{HF}$ is liable to be considered here. Hypoalbuminemia is prevalent in HF patients, in approximately one-third of those in chronic state and in up to half of all hospitalized patients $[61,62]$. Hypoalbuminemia $(\leq 3.2 \mathrm{~g} / \mathrm{dL})$ is an important predictor of in-hospital mortality among elderly patients who were admitted for acute HF [63]. Hypoalbuminemia appears to be reliable in predicting mortality among individuals with HF and a reduced ejection fraction $(<40 \%)$, both in acute [64-66] and chronic states [61]. However, results from individuals of $\mathrm{HF}$ and preserved ejection fraction (HFpEF) in two retrospective studies differed. Uthamalingam et al. evaluated $37 \mathrm{HFpEF}$ patients who were admitted for acute decompensated HF; hypoalbuminemia was not found to be clearly associated with 1-year mortality [64]. In another study conducted by Liu et al. enrolling more participants, i. e. 611 individuals consecutively admitted for acute decompensated HF with preserved ejection fraction, hypoalbuminemia was found to be useful in predicting 1-year all-cause mortality after adjusting the baseline factors [62].

SA and HF risk association was investigated in elderly patients. A community-based cohort study investigated 2907 healthy individuals aged between 70 and 79 . Those with low baseline SA concentrations were at risk for developing HF, but this risk declined over time [67]. In the Cardiovascular Health Study, enrolling 5450 healthy individuals aged $\geq 65$ years, hypoalbuminemia was found to be significantly associated with incident HF in 10 years by using propensity matched analysis [68]. Since the established study reported a significant association between echocardiographic parameters and HF, the impact of SA on cardiac dysfunction should be investigated [69]. This would not only elucidate the link between SA and HF but also aid early detection of subclinical cardiac dysfunction in healthy individuals.

\section{Conclusions}

The measurement of SA is widely available and popular in current medical institutes because of its perceived reliability and low cost. Since SA implicates several important physiological functions, the determined SA concentration reflects physical or healthy status and thereby predicts the prognosis. It is clear that an improvement in risk-specific approaches, which can provide robust and accurate risk prediction, are needed to curb the ongoing burden of CVD [70]. We have to be acquainted with applications of albumin in comprehensive CV fields. Tailored therapies, such as nutritional intervention and direct albumin administration, in individuals with low SA concentration, considered as high-risk groups, should be investigated with randomized placebo-controlled trials to understand its clinical efficacy and safety [71]. In addition, it is warranted to continue exploring the additional roles of albumin in CVD.

\section{Abbreviations}

ARIC: Atherosclerosis Risk In Communities Study; CAD: Coronary artery disease: CV: Cardiovascular; CVD: Cardiovascular disease; HF: Heart failure; HFpEF: Heart failure with preserved ejection fraction; MI: Myocardial infarction;

NHEFS: National Health and Nutrition Examination Survey Epidemiologic Follow-up Study; NO: Nitric oxide; PAD: Peripheral artery disease;

PCl: Percutaneous coronary intervention; RNS: Reactive nitrogen species; ROS: Reactive oxygen species

\section{Acknowledgments}

All authors acknowledge the support from MacKay Memorial Hospital (MMH-E106-03).

\section{Funding}

This review received no specific funding from any agency in the public, commercial, or not-for-profit sectors.

\section{Availability of data and materials}

Not applicable

\section{Authors' contributions}

SCC drafted the manuscript. CYC had made substantial contributions to the section on albumin and prognosis in coronary artery disease of this review. CFL participated in editing table and graph of the prognostic value of serum albumin. HIY reviewed and edited the manuscript. All authors read and approved the final manuscript.

Ethics approval and consent to participate

Not applicable

\section{Consent for publication}

Not applicable

\section{Competing interests}

All authors have no competing interests to be declared.

\section{Publisher's Note}

Springer Nature remains neutral with regard to jurisdictional claims in published maps and institutional affiliations.

\section{Author details}

${ }^{1}$ Department of Critical Care Medicine, MacKay Memorial Hospital, No. 92, Sec. 2, Zhongshan N. Rd, Taipei City 10449, Taiwan, Republic of China.

${ }^{2}$ Cardiovascular Division, Department of Internal Medicine, MacKay Memorial Hospital, Mackay Medical College, No. 92, Sec. 2, Zhongshan N. Rd, Taipei

City 10449, Taiwan, Republic of China.

Received: 27 July 2017 Accepted: 31 October 2017

Published online: 10 November 2017

\section{References}

1. Peters T Jr. 1 - Historical Perspective. In: All about albumin. San Diego: Academic Press; 1995. p. 1-8.

2. Nicholson JP, Wolmarans MR, Park GR. The role of albumin in critical illness. Br J Anaesth. 2000;85(4):599-610.

3. Quinlan GJ, Martin GS, Evans TW. Albumin: biochemical properties and therapeutic potential. Hepatology, 2005:41(6):1211-9.

4. Danesh J, Collins R, Appleby P, Peto R. Association of fibrinogen, C-reactive protein, albumin, or leukocyte count with coronary heart disease: meta-analyses of prospective studies. JAMA. 1998;279(18):1477-82.

5. Beatty AL, IA K, Bibbins-Domingo K, Christenson RH, DeFilippi CR, Ganz P, et al. Traditional risk factors versus biomarkers for prediction of secondary events in patients with stable coronary heart disease: from the heart and soul study. J Am Heart Assoc. 2015;4(7):e001646.

6. Peters T Jr. 2 - The Albumin Molecule: Its Structure and Chemical Properties. In: All About Albumin. San Diego: Academic Press; 1995. p. 9-II.

7. Kragh-Hansen U. Human Serum Albumin: A Multifunctional Protein. In: Otagiri M, Chuang VTG, editors. Albumin in medicine: pathological and clinical applications. Singapore: Springer Singapore; 2016. p. 1-24. 
8. Phillips A, Shaper AG, Whincup PH. Association between serum albumin and mortality from cardiovascular disease, cancer, and other causes. Lancet. 1989; 2(8677):1434-6.

9. Boldt J. Use of albumin: an update. BJA. Br J Anaesth. 2010;104(3):276-84.

10. Bern M, Sand KM, Nilsen J, Sandlie I, Andersen JT. The role of albumin receptors in regulation of albumin homeostasis: implications for drug delivery. J Control Release. 2015;211:144-62.

11. Arnal M, Obled C, Attaix D, Patureau-Mirand P, Bonin D. Dietary control of protein turnover. Diabete Metab. 1987;13(6):630-42.

12. Dich J, Hansen SE, Thieden HI. Effect of albumin concentration and colloid osmotic pressure on albumin synthesis in the perfused rat liver. Acta Physiol Scand. 1973;89(3):352-8.

13. Oratz M, Rothschild MA, Schreiber SS. Effect of dextran infusions on protein synthesis by hepatic microsomes. Am J Phys. 1970;218(4):1108-12.

14. De Feo P, Gaisano MG, Haymond MW. Differential effects of insulin deficiency on albumin and fibrinogen synthesis in humans. J Clin Invest. 1991;88(3):833-40.

15. Tessari P. Protein metabolism in liver cirrhosis: from albumin to muscle myofibrils. Curr Opin Clin Nutr Metab Care. 2003;6(1):79-85.

16. Johnson TR, Rudin SD, Blossey BK, Ilan J, Ilan J. Newly synthesized RNA: simultaneous measurement in intact cells of transcription rates and RNA stability of insulin-like growth factor I, actin, and albumin in growth hormonestimulated hepatocytes. Proc Natl Acad Sci U S A. 1991;88(12):5287-91.

17. Nawa K, Nakamura T, Kumatori A, Noda C, Ichihara A. Glucocorticoid-dependent expression of the albumin gene in adult rat hepatocytes. J Biol Chem. 1986; 261(36):16883-8.

18. Joles JA, Willekes-Koolschijn N, Koomans HA. Hypoalbuminemia causes high blood viscosity by increasing red cell lysophosphatidylcholine. Kidney Int. 1997:52(3):761-70.

19. McGinley E, Lowe GD, Boulton-Jones M, Forbes CD, Prentice CR. Blood viscosity and haemostasis in the nephrotic syndrome. Thromb Haemost. 1983;49(3):155-7.

20. Demling RH. Effect of plasma and interstitial protein content on tissue edema formation. Curr Stud Hematol Blood Transfus. 1986;53:36-52.

21. Keaney JF Jr, Simon DI, Stamler JS, Jaraki O, Scharfstein J, Vita JA, et al. NO forms an adduct with serum albumin that has endothelium-derived relaxing factor-like properties. J Clin Invest. 1993;91(4):1582-9.

22. Rubbo H, Parthasarathy S, Barnes S, Kirk M, Kalyanaraman B, Freeman BA. Nitric oxide inhibition of lipoxygenase-dependent liposome and low-density lipoprotein oxidation: termination of radical chain propagation reactions and formation of nitrogen-containing oxidized lipid derivatives. Arch Biochem Biophys. 1995;324(1):15-25.

23. Stocker R, Glazer AN, Ames BN. Antioxidant activity of albumin-bound bilirubin. Proc Natl Acad Sci U S A. 1987:84(16):5918-22.

24. Gandrille $S$, Aiach M. Albumin concentration influences fibrinolytic activity in plasma and purified systems. Fibrinolysis. 1990:4(4):225-32.

25. Mikhailidis DP, Mikhailidis AM, Dandona P. Effect of human plasma proteins on stabilisation of platelet anti-aggregatory activity of prostacyclin. Ann Clin Biochem. 1982;19(Pt 4):241-4

26. Gabay C, Kushner I. Acute-phase proteins and other systemic responses to inflammation. N Engl J Med. 1999;340(6):448-54.

27. Varma R, Michos GA, Varma RS, Brown RD Jr. The protein-bound carbohydrates of seromucoid from normal human serum. J Clin Chem Clin Biochem. 1983;21(5):273-7.

28. Sankaranarayanan S, De la Llera-Moya M, Drazul-Schrader D, Phillips MC, Kellner-Weibel G, Rothblat GH. Serum albumin acts as a shuttle to enhance cholesterol efflux from cells. J Lipid Res. 2013;54(3):671-6.

29. Meierhofer T, van den Elsen JM, Cameron PJ, Munoz-Berbel $X$, Jenkins AT. The interaction of serum albumin with cholesterol containing lipid vesicles. J Fluoresc. 2010;20(1):371-6.

30. Fielding CJ, Moser K. Evidence for the separation of albumin- and apo A-Idependent mechanisms of cholesterol efflux from cultured fibroblasts into human plasma. J Biol Chem. 1982;257(18):10955-60.

31. Gillum RF, Makuc DM. Serum albumin, coronary heart disease, and death. Am Heart J. 1992;123(2):507-13.

32. Kuller LH, Eichner JE, Orchard TJ, Grandits GA, McCallum L, Tracy RP. The relation between serum albumin levels and risk of coronary heart disease in the multiple risk factor intervention trial. Am J Epidemiol. 1991;134(11):1266-77.

33. Darne B, Ducimetiere P, Guize L. Serum albumin and mortality. (letter). Lancet. 1990;335(8685):350-1.

34. Djousse L, Rothman KJ, Cupples LA, Levy D, Ellison RC. Serum albumin and risk of myocardial infarction and all-cause mortality in the Framingham offspring study. Circulation. 2002;106(23):2919-24.
35. Umeki $Y$, Adachi H, Enomoto M, Fukami A, Nakamura S, Nohara Y, et al. Serum albumin and Cerebro-cardiovascular mortality during a 15-year study in a community-based cohort in Tanushimaru, a cohort of the seven countries study. Intern Med. 2016;55(20):2917-25.

36. Nelson JJ, Liao D, Sharrett AR, Folsom AR, Chambless LE, Shahar E, et al. Serum albumin level as a predictor of incident coronary heart disease: the atherosclerosis risk in communities (ARIC) study. Am J Epidemiol. 2000;151(5):468-77.

37. Corti MC, Salive ME, Guralnik JM. Serum albumin and physical function as predictors of coronary heart disease mortality and incidence in older persons. J Clin Epidemiol. 1996:49(5):519-26.

38. Weijenberg MP, Feskens EJ, Souverijn JH, Kromhout D. Serum albumin, coronary heart disease risk, and mortality in an elderly cohort. Epidemiology. 1997;8(1):87-92.

39. Oduncu V, Erkol A, Karabay CY, Kurt M, Akgun T, Bulut M, et al. The prognostic value of serum albumin levels on admission in patients with acute ST-segment elevation myocardial infarction undergoing a primary percutaneous coronary intervention. Coron Artery Dis. 2013:24(2):88-94.

40. Sujino Y, Tanno J, Nakano S, Funada S, Hosoi Y, Senbonmatsu T, et al. Impact of hypoalbuminemia, frailty, and body mass index on early prognosis in older patients ( $>/=85$ years) with ST-elevation myocardial infarction. J Cardiol. 2015; 66(3):263-8.

41. Plakht $Y$, Gilutz $H$, Shiyovich $A$. Decreased admission serum albumin level is an independent predictor of long-term mortality in hospital survivors of acute myocardial infarction. Soroka acute myocardial infarction II (SAMI-II) project. Int J Cardiol. 2016;219:20-4.

42. Hartopo AB, Gharini PP, Setianto BY. Low serum albumin levels and in-hospital adverse outcomes in acute coronary syndrome. Int Heart J. 2010;51(4):221-6

43. Bhamidipati CM, LaPar DJ, Mehta GS, Kern JA, Upchurch Jr GR, Kron IL, et al. Albumin is a better predictor of outcomes than body mass index following coronary artery bypass grafting. Surgery. 2011;150(4):626-34.

44. Wada H, Dohi T, Miyauchi K, Shitara J, Endo H, Doi S, et al. Impact of serum albumin levels on long-term outcomes in patients undergoing percutaneous coronary intervention. Heart Vessel. 2017;32(9):1085-92

45. Kurtul A, Murat SN, Yarlioglues M, Duran M, Ocek AH, Koseoglu C, et al. Usefulness of serum albumin concentration to predict high coronary SYNTAX score and in-hospital mortality in patients with acute coronary syndrome. Angiology. 2016;67(1):34-40.

46. Murat SN, Kurtul A, Yarlioglues M. Impact of serum albumin levels on contrastinduced acute kidney injury in patients with acute coronary syndromes treated with percutaneous coronary intervention. Angiology. 2015;66(8):732-7.

47. Kurtul A, Ocek AH, Murat SN, Yarlioglues M, Demircelik MB, Duran M, et al. Serum albumin levels on admission are associated with angiographic noreflow after primary percutaneous coronary intervention in patients with STsegment elevation myocardial infarction. Angiology. 2015;66(3):278-85.

48. Celik IE, Yarlioglues M, Kurtul A, Duran M, Koseoglu C, Oksuz F, et al. Preprocedural albumin levels and risk of in-stent restenosis after coronary stenting with bare-metal stent. Angiology. 2016;67(5):478-83.

49. Chien SC, Chen CY, Leu HB, CH S, Yin WH, Tseng WK, et al. Association of low serum albumin concentration and adverse cardiovascular events in stable coronary heart disease. Int J Cardiol. 2017;241:1-5.

50. Gillum RF, Ingram DD, Makuc DM. Relation between serum albumin concentration and stroke incidence and death: the NHANES I epidemiologic follow-up study. Am J Epidemiol. 1994;140(10):876-88.

51. WH X, Dong C, Rundek T, Elkind MS, Sacco RL. Serum albumin levels are associated with cardioembolic and cryptogenic ischemic strokes: northern Manhattan study. Stroke. 2014;45(4):973-8.

52. Hostmark AT, Tomten SE. Serum albumin and self-reported prevalence of stroke: a population-based, cross-sectional study. Eur J Cardiovasc Prev Rehabil. 2006;13(1):87-90.

53. Dziedzic T, Slowik A, Szczudlik A. Serum albumin level as a predictor of ischemic stroke outcome. Stroke. 2004;35(6):e156-8.

54. Hill MD, Martin RH, Palesch YY, Moy CS, Tamariz D, Ryckborst KJ, et al. Albumin Administration in Acute Ischemic Stroke: safety analysis of the ALIAS part 2 multicenter trial. PLOS One. 2015;10(9):e0131390.

55. Martin RH, Yeatts SD, Hill MD, Moy CS, Ginsberg MD, Palesch YY, ALIAS. (Albumin in acute ischemic stroke) trials: analysis of the combined data from parts 1 and 2. Stroke. 2016:47(9):2355-9.

56. O'Hare AM, Hsu CY, Bacchetti P, Johansen KL. Peripheral vascular disease risk factors among patients undergoing hemodialysis. J Am Soc Nephrol. 2002;13(2):497-503. 
57. Beddhu S, Kaysen GA, Yan G, Sarnak M, Agodoa L, Ornt D, et al. Association of serum albumin and atherosclerosis in chronic hemodialysis patients. Am J Kidney Dis. 2002;40(4):721-7.

58. Tsai MH, Liou HH, Leu JG, Yen MF, Chen HH. Sites of peripheral artery occlusive disease as a predictor for all-cause and cardiovascular mortality in chronic hemodialysis. PLoS One. 2015;10(6):e0128968.

59. Ishii H, Aoyama T, Takahashi H, Kamoi D, Tanaka M, Yoshikawa D, et al. Serum albumin and C-reactive protein levels predict clinical outcome in hemodialysis patients undergoing endovascular therapy for peripheral artery disease. Atherosclerosis. 2013;227(1):130-4.

60. Schillinger M, Exner M, Mlekusch W, Amighi J, Sabeti S, Schlager O, et al. Serum albumin predicts cardiac adverse events in patients with advanced atherosclerosis - interrelation with traditional cardiovascular risk factors. Thromb Haemost. 2004;91(3):610-8.

61. Horwich TB, Kalantar-Zadeh K, MacLellan RW, Fonarow GC. Albumin levels predict survival in patients with systolic heart failure. Am Heart J. 2008; 155(5):883-9.

62. Liu M, Chan CP, Yan BP, Zhang Q, Lam YY, Li RJ, et al. Albumin levels predict survival in patients with heart failure and preserved ejection fraction. Eur J Heart Fail. 2012;14(1):39-44.

63. Kinugasa $Y$, Kato M, Sugihara S, Hirai M, Kotani K, Ishida K, et al. A simple risk score to predict in-hospital death of elderly patients with acute decompensated heart failure-hypoalbuminemia as an additional prognostic factor. Circ J. 2009; 73(12):2276-81.

64. Uthamalingam S, Kandala J, Daley M, Patvardhan E, Capodilupo R, Moore SA, et al. Serum albumin and mortality in acutely decompensated heart failure. Am Heart J. 2010;160(6):1149-55.

65. Polat N, Aydin M, Yildiz A, Acet H, Akil MA, Bilik MZ, et al. The prognostic significance of serum albumin in patients with acute decompensated systolic heart failure. Acta Cardiol. 2014;69(6):648-54

66. Bonilla-Palomas JL, Gamez-Lopez AL, Moreno-Conde M, Lopez-Ibanez MC, Anguita-Sanchez M, Gallego de la Sacristana A, et al. Hypoalbuminemia in acute heart failure patients: causes and its impact on hospital and longterm mortality. J Card Fail. 2014;20(5):350-8.

67. Gopal DM, Kalogeropoulos AP, Georgiopoulou W, Tang WW, Methvin A Smith $A L$, et al. Serum albumin concentration and heart failure risk the health, aging, and body composition study. Am Heart J. 2010;160(2):279-85.

68. Filippatos GS, Desai RV, Ahmed MI, Fonarow GC, Love TE, Aban IB, et al. Hypoalbuminaemia and incident heart failure in older adults. Eur J Heart Fail. 2011;13(10):1078-86.

69. Hung C-L, Wu Y-J, Liu C-C, Hou CJ-Y, Hung T-C, Yeh H-I, et al. Age-related ventricular remodeling is an independent risk for heart failure symptoms in subjects with preserved systolic function. International Journal of Gerontology. 2011:5(1):17-24.

70. Lloyd-Jones DM. Cardiovascular risk prediction: basic concepts, current status, and future directions. Circulation. 2010;121(15):1768-77.

71. Lim S-L, Lye J. Nutritional intervention incorporating expedited $10 \mathrm{~g}$ protein counter (EP-10) to improve the albumin and transferrin of chronic hemodialysis patients. ISRN Nutrition. 2013;2013:396570.

\section{Submit your next manuscript to BioMed Central and we will help you at every step:}

- We accept pre-submission inquiries

- Our selector tool helps you to find the most relevant journal

- We provide round the clock customer support

- Convenient online submission

- Thorough peer review

- Inclusion in PubMed and all major indexing services

- Maximum visibility for your research

Submit your manuscript at www.biomedcentral.com/submit 